\title{
Sprint Swimming Performance of Juvenile European Sea Bass
}

\author{
JAY A. NELSON* \\ Department of Biological Sciences, Towson University, \\ Towson, Maryland 21252-0001, USA \\ Guy Claireaux \\ Centre de Recherche sur les Écosystèmes Marins et Aquacoles, CNRS-IFREMER, Place du \\ Séminaire, BP 5, 17137, L'Houmeau, France
}

\begin{abstract}
Despite its potential for determining animal success in a variety of ecologically important situations, very little is known about the sprint swimming performance of fishes. To evaluate whether selection on sprint swimming performance occurs in the wild, one must first demonstrate measurable and reproducible variation of sprint performance. In this study, we employ a computercontrolled laser detection system to study the sprint performance of 75 juvenile European sea bass Dicentrarchus labrax raised under uniform conditions in the laboratory. This percichthyid is a prized sport and food fish in Europe and similar ecologically to the North American striped bass Morone saxatilis. Individual European sea bass were subjected to endurance swimming performance tests and had their active metabolic rates measured to test hypotheses concerning relationships between these measures and sprint performance. Maximal velocity obtained by an individual during repetitive sprint performance trials was very reproducible but varied substantially among individuals. Consecutive sprint trials with an individual revealed that maximal capacity for sprinting could only be ascertained through multiple trials (at least four). The sprint performance test described in this study should be useful for large-scale studies in which investigators desire performance information on a large number of animals relatively quickly. However, active metabolic rate measurements and an endurance test were not considered effective performance measures for juvenile European sea bass, and there was no relationship between sprint swimming performance and either of the tests.
\end{abstract}

Different types of swimming performance are required by some fishes to successfully reach their reproductive potential (Reidy et al. 2000; Nelson et al. 2002). Predator-prey interactions generally last a few seconds and test the operation of neuronal pathways encompassing processes from sensation through activation of the neuromuscular junction as well as testing the twitch contraction kinetics of muscle performing at maximal power output. In contrast, migrations will tax the fish's ability to sustain aerobic muscular contractions for days. Despite this diversity of demands placed upon the swimming apparatus of fishes, the vast majority of studies on fish swimming performance use only a single trial of a single swimming test to assess locomotor performance (see Beamish 1978 for a review; Hammer 1995; Plaut 2001; Nelson et al. 2002). In addition, few studies have examined performance between the scales of starting from a dead stop ("fast-start performance") and long-distance swims (critical swimming and en-

\footnotetext{
* Corresponding author: jnelson@towson.edu
}

Received May 25, 2004; accepted April 18, 2005 Published online August 29, 2005 durance tests). If successful inference is ever to be made about the role of locomotor performance in determining success of fish in the wild, multiple performance tests mirroring the types of swimming required in nature must be employed (locomotor performance space: Bennett and Huey 1990; Nelson et al. 2002). This study examines sprint swimming performance in a cohort of juvenile European sea bass Dicentrarchus labrax, an economically important fish in western Europe. This percichthyid is ecologically similar to its confamiliar, the North American striped bass Morone saxatilis.

European sea bass require some minimal performance capacity at several temporal scales to reach reproductive age. A pelagic fish, the predatory European sea bass swims strongly to capture its smaller prey (mostly fish and prawns). Capture is accomplished with a burst of speed initiated by a pronounced undulation of the caudal peduncle (C-start), followed by two or more rapid undulations of the caudal fin as the fish thrusts forward to encounter its prey (subcarangiform cruiser or sprinter; Pickett and Pawson 1994). Predator avoidance is probably accomplished in a similar 
manner. Furthermore, European sea bass juveniles occupy shallow tidal lagoons and estuaries susceptible to environmental change. As they grow, they shuttle between these habitats and deeper water as episodic low temperature and hypoxia dictate, often against substantial tidal currents that may require bursts of swimming to be negotiated (Pawson and Pickett 1987). Juveniles have also been observed holding station in strong tidal currents and are subject to predation by pelagic fishes and several types of birds (Pickett and Pawson 1994). Thus, sprinting performance could be critical to the survival of juvenile European sea bass. When they reach maturity, European sea bass undergo open ocean migrations in the autumn between inshore feeding areas and offshore prespawning areas and return to feeding areas in the spring (Pawson and Pickett 1987). Therefore, sustained swimming performance might also be essential to the successful completion of the European sea bass life cycle.

This study was undertaken to evaluate the efficacy of a new sprint performance test (Reidy et al. 2000; Nelson et al. 2002) with a new species of fish and to determine whether this sprint performance test has potential as a fitness surrogate in European sea bass (Bennett and Huey 1990). The first step toward establishing a test's utility as a fitness surrogate is to establish its reproducibility and to identify measurable variation among individuals. Several types of laboratory measures of performance have been shown to be reproducible over time in fish; generally, interindividual variation has exceeded intraindividual variation of repeat performances in these studies (e.g., Claireaux et al. 1995; Gregory and Wood 1998; Kolok 1999; Reidy et al. 2000; Nelson et al. 2002). However, these studies encompass a small number of species and very few types of performance. A second objective of this study was to test for relationships between the new sprint performance test, several other common laboratory performance tests, and measures of animal shape.

\section{Methods}

Fish collection and maintenance.-Ninety-seven juvenile European sea bass of both sexes and progeny of the same broodstock were obtained from a local hatchery in mid-June 2001 (Ferme Marine des Baleines, Ile de Ré, France) and brought to the Centre de Recherche sur les Ecosystèmes Marins et Aquacoles (CREMA) in L'Houmeau, France. The broodstock was four generations removed from the wild and had a $10 \%$ annual renewal rate with the wild stock. Fish size was deliberately restricted to a narrow range to minimize scaling effects (size, $15.87 \pm 1.23 \mathrm{~cm}$ [mean $\pm \mathrm{SD}]$ ); size range, $13.4-17.9 \mathrm{~cm}$ total length (TL); mass, 40.44 $\pm 9.74 \mathrm{~g}$ ); mass range, 23.7-67.0 g) and tradeoffs between growth rate and swimming performance (e.g., Billerbeck et al. 2001). Cultured fish were chosen for this experiment to minimize phenotypic variance resulting from differential ontogenetic exposure to predators and environments. Fish were held in three 500-L indoor tanks supplied with recirculated and filtered natural seawater (28-32\%o at $20^{\circ} \mathrm{C}$; water renewal rate $=30-50 \% /$ week). Fish were kept under natural photoperiod conditions and were fed three times per week with commercial dry pellets to satiation (Bar D PerformNatura 4.5; Sica du Gouessant, Lamballe, France). Feeding was discontinued $24 \mathrm{~h}$ before any manipulation of the animals and at least $3 \mathrm{~d}$ before a swimming performance test. Fish were held for at least 2 months before experimentation. Between August 30 and September 3, 2001, the animals were successively anesthetized (2-phenoxyethanol; $0.3 \mathrm{~mL} /$ $\mathrm{L})$, weighed (g), measured for length, width, and depth $(\mathrm{cm})$, and tagged by inserting a passive integrated transponder subcutaneously behind the dorsal fin for purposes of individual identification. Fish were allowed a minimum of 1 week to recover from tagging or a performance test before being used in another test.

Sprint performance.-The sprint performance chamber was modeled after that described in Nelson et al. (2002) but was modified for the dimensions of juvenile European sea bass and employed numerous advances in electronic technology (detailed below). Dimensions of the raceway were $2.00 \mathrm{~m}$ (length) $\times 0.25 \mathrm{~m}$ (width) $\times 0.30 \mathrm{~m}$ (height). Light-emitting laser diodes (OnPoint Lasers, Inc., Eden Prairie, Minnesota, and Selectronic, Lille, France) with a power output of $5 \mathrm{~mW}$, a wavelength of $645-670 \mathrm{~nm}$, and a beam width of $1.1 \mathrm{~mm}$ were placed at intervals of $0,0.02,0.04$, $0.08,0.16,0.41,0.66$, and $0.91 \mathrm{~m}$ from the point at which a fish would begin its sprint. The lasers were mounted in front of clear glass windows on one side of the raceway. A 5-mm glass rod was attached to the front of the laser lens. This rod refracted the beam to project a vertical plane or "curtain of light" across the raceway.

The laser light was detected on the opposite side of the chamber by eight arrays of Photodarlington detectors (Honeywell International, Inc., Morristown, New Jersey; 9 sensors/array, 72 sensors total) of detection wavelength $580-720 \mathrm{~nm}$. Indi- 
vidual sensors in an array were positioned vertically $1 \mathrm{~cm}$ from the bottom and then every $1.5 \mathrm{~cm}$ apart to a height of $13 \mathrm{~cm}, 1 \mathrm{~cm}$ below the "fill" line. This separation distance was empirically determined to assure that a beam would be broken within the first centimeter of a European sea bass's body (for the size and shape of fish used in this experiment). Depth was restricted to $14 \mathrm{~cm}$ to limit vertical sprint trajectories.

When activated by light, the Photodarlington detector array puts out a $5-\mathrm{V}$ signal to one of eight inputs on a Daqboard 200 data acquisition board (IOtech, Inc., Bedford Heights, Ohio) inside a PCcompatible computer. When all 9 sensors in an array are saturated with light, the output is a constant $5 \mathrm{~V}$. However, disruption of the light path to any one sensor of an array causes the output from the entire array to drop below $1 \mathrm{~V}$. When armed, the computer scans the first array at a rate of 19.2 $\mathrm{kHz}$ and begins collecting data when a fish breaks the first light beam. Data were assimilated with Daqview software (IOtech), while velocity and acceleration were calculated from the times of breakage of subsequent laser beams and the distance between detector arrays utilizing a propriety Labview (National Instruments Corporation, Austin, Texas) routine (G. Claireaux, unpublished).

Sprint trials took place from October 12 to November 2, 2001. At least $0.5 \mathrm{~h}$ before the initiation of a sprint trial, a fish was netted from its holding tank and placed into the sprint chamber. The fish voluntarily oriented to an area immediately before the first detector array because a preferred black background was placed at that location. A trial began by observing the fish facing forward close to the starting line and an investigator grasping (or attempting to grasp) the caudal peduncle of the fish. After tactile (or attempted) stimulation, the fish would burst down the raceway toward a shadow at the end of the chamber and its velocity was recorded. Mirroring previous results for Atlantic cod Gadus morhua (Nelson et al. 2002), tactile stimulation proved superior to auditory, electrical, and visual stimuli in preliminary trials and was adopted as the stimulus of choice. Fish often returned to the dark area at the starting line of their own accord, but sometimes it was necessary to chase them back to the start location. Regardless of how the fish returned to the start location, a minimum of 5 min elapsed between the time of last human contact with a fish and initiation of a subsequent sprint trial. Fish were sprinted a minimum of four times $(\bar{X}=5.5)$ and until the investigator was satisfied that three quality trials (straight path, motivated fish) had been obtained. Only the top three trials were analyzed.

Exercise metabolism.-A Brett-type swim tunnel respirometer (STR; $39 \mathrm{~L}$; Claireaux and Lagardère 1999) was used to measure each fish's oxygen consumption rate $\left(\dot{V} \mathrm{O}_{2}\right)$ at three swimming speeds $(U)$. The working section of the tunnel was $60.0 \mathrm{~cm}$ in length and $11.5 \mathrm{~cm}$ in diameter. The upstream section of the swimming section was darkened to motivate the fish to occupy an upstream position. Water temperature was controlled at $20.0 \pm 0.2^{\circ} \mathrm{C}$. A variable-speed pump propelled the water at a constant velocity. A plastic honeycomb grid and deflectors were inserted in the recirculation loop to promote rectilinear flow and uniform velocity profiles. Flow characteristics were assessed visually by observing dye flow patterns. A Marsh-McBirney 200 flowmeter (Frederick, Maryland) was used to calibrate water velocity to revolutions of the pump impeller. An average of eight readings taken at different crosssectional positions of the swim tunnel was used as the water velocity at a given controller setting. The relationship between pump revolutions $(\mathrm{Hz})$ and water velocity in meters per second constructed from 14 separate controller settings between 0.10 and $0.95 \mathrm{~m} / \mathrm{s}$ was linear (water velocity $=0.03 \times$ controller setting $\left.-0.01 ; r^{2}=0.999\right)$. Swimming speeds were routinely corrected for maximum solid-blocking effects with the following equation derived from Bell and Terhune (1970):

$$
V_{F}=V_{T}\left(1+\varepsilon_{s}\right),
$$

where $V_{F}$ is the effective water velocity, $V_{T}$ is the average water velocity in the empty swimming section, and $\varepsilon_{s}$ is the fractional error in $V_{T}$ caused by the presence of the fish. The factor $\varepsilon_{s}$ is calculated as follows:

$$
\varepsilon_{s}=\tau \times \lambda \times\left(\frac{A_{0}}{A_{T}}\right)^{3 / 2}
$$

where $\tau$ is a dimensionless factor depending on the tunnel cross-sectional shape $(0.8), \lambda$ is a shape factor for the fish $(0.5 \times$ length/thickness $), A_{0}$ is the cross-sectional area of the fish, and $A_{T}$ is the cross-sectional area of the swim chamber.

Water oxygen concentration was recorded continuously with an Orbisphere Laboratories (Vésenaz, Switzerland) oxygen meter (Model 2610) and probe (Model 27141) in an external loop interfaced to a PC-compatible computer. Fish $\dot{V} \mathrm{O}_{2}$ was calculated from the rate of oxygen depletion according to the equation 


$$
\dot{V} \mathrm{O}_{2}=\text { slope } \cdot\left(\mathrm{VOL}_{\text {resp }}-\mathrm{VOL}_{\text {fish }}\right)
$$

where $\dot{V} \mathrm{O}_{2}\left(\mathrm{mgO}_{2} / \mathrm{h}\right)$ is oxygen consumption, slope is the decline in oxygen concentration with time $\left[\left(\mathrm{mgO}_{2} / \mathrm{h}\right)=\Delta\left(\mathrm{O}_{2}\right)_{\mathrm{H} 2 \mathrm{O}} / \Delta\right.$ time $\left.^{-1}\right], \mathrm{VOL}_{\text {resp }}$ (l) is the volume of the STR, and $\mathrm{VOL}_{\text {fish }}$ is the volume of the fish assuming a fish density of $1.0 \mathrm{~g} /$ $\mathrm{mL}$. Oxygen consumption was further adjusted for differences in body mass according to an empirically derived relationship,

$$
\dot{V} \mathrm{O}_{2 \text { corr }}=\dot{V} \mathrm{O}_{2 \text { meas }} \cdot\left(\frac{m_{\text {fish }}}{m_{\text {std }}}\right)^{1-A}
$$

where $\dot{V} \mathrm{O}_{2 \text { corr }}$ is the corrected oxygen consumption, $\dot{V} \mathrm{O}_{2 \text { meas }}$ is the actual measured oxygen consumption, $m_{\text {fish }}$ is the mass of the current fish, $m_{\text {std }}$ is the mass of the standard fish, and $A$ is the empirically derived mass coefficient of 0.77 (Claireaux, unpublished). The level of oxygen saturation in the STR was never allowed to fall below $80 \%$. The oxygen probe was calibrated daily with air-saturated water.

Metabolism experiments took place from September 7 to October 31, 2001. At least $16 \mathrm{~h}$ before swimming, a fish was netted from its holding tank and either placed into the STR or into a $13-\mathrm{cm}-$ diameter $\times 1$-m-long supplementary acclimation tube designed to acquaint the fish with a tunnel environment.

During acclimation, the fish were exposed to a $0.10-\mathrm{m} / \mathrm{s}$ current and were trained to avoid resting at the back of the tube by the presence of a light gradient. Fish acclimated in the supplementary tube were gently slid into the STR at least $1 \mathrm{~h}$ before the start of an experiment. There were no significant differences in endurance performance or exercise metabolism between animals acclimated in the STR or the supplementary tube ( $t$ test, $P>0.05$ for all tests).

An experiment began by increasing the water velocity from $0.10 \mathrm{~m} / \mathrm{s}$ to $0.45 \mathrm{~m} / \mathrm{s}$ at a rate of 0.05 $\mathrm{m} \cdot \mathrm{s}^{-1} \cdot \mathrm{min}^{-1}$. Fish swam at $0.45 \mathrm{~m} / \mathrm{s}$ for $0.5 \mathrm{~h}$, whereupon the water velocity was increased to $0.65 \mathrm{~m} / \mathrm{s}$ at a rate of $0.05 \mathrm{~m} \cdot \mathrm{s}^{-1} \cdot \mathrm{min}^{-1}$. The water velocity was further increased to $0.85 \mathrm{~m} / \mathrm{s}$ at a rate of $0.05 \mathrm{~m} \cdot \mathrm{s}^{-1} \cdot \mathrm{min}^{-1}$ if the animal completed $0.5 \mathrm{~h}$ at $0.65 \mathrm{~m} / \mathrm{s}$. The fish was allowed to swim at this velocity for $2 \mathrm{~h}$ or until it was exhausted, whichever came first. Exhaustion was defined as the inability of a fish to remove itself from the posterior retaining grid after being prodded with a blunt probe or a brief decrease in water velocity. Endurance performance was recorded as the total dis- tance swum during the test after correction for solid blocking.

Oxygen consumption was measured from $5 \mathrm{~min}$ to $25 \mathrm{~min}$ of each 30 -min interval. This protocol resulted in multiple measurements of oxygen consumption at the $0.85-\mathrm{m} / \mathrm{s}$ velocity for many fish, in which case the average oxygen consumption was analyzed. After each run, the fish was removed from the swimming chamber, returned to a holding tank, and the STR was resealed for determination of background oxygen consumption by microorganisms.

Data analysis.-Statistical analyses were performed with Statistica (StatSoft 1994). The conformance of distributions to the normal distribution was tested with the Kolmogorov-Smirnov single sample cumulative distribution test. The one measurement that was not normally distributed (endurance performance) was log transformed before statistical analysis. The repeatability of separate sprint trials was evaluated by calculating Spearman's rank correlation coefficient $(r)$ between the top three trials. Measurements of length, mass, depth, and width were all highly autocorrelated such that a regression analysis of these variables against performance variables would suffer from the problem of multicollinearity (Slinker and Glantz 1985). Thus, to analyze the effects of body shape, size, or both on the various performance measurements, a factor analysis was performed on the four measurements. The first two factors that explained $97 \%$ of the variance were used as indicators of morphology and regressed against performance variables. There was a trend for oxygen consumption to decline with the changing season. This trend was significant for the $0.45-\mathrm{m} / \mathrm{s}$ swimming speed only $(F=15.34 ; P=0.002)$. Thus, oxygen consumption at this speed was corrected to a standard date midway through the experiment according to Reidy et al. (2000). Interrelationships among the various measurements were tested with least-squares regression analysis. Conformance of distributions to expected values was tested with a chi-square test.

\section{Results}

\section{Sprint Performance}

Sprint performance differences between the 75 individual European sea bass were far greater than differences between repetitive trials of a given individual (Figures 1,2). The top velocity reached for a given trial (a raceway interval $0.08 \mathrm{~m}$ or longer) was the only parameter analyzed from the 


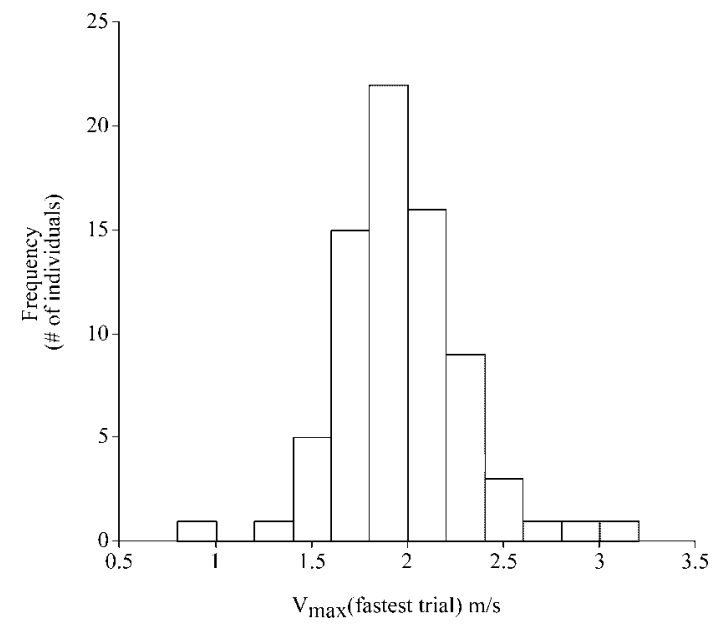

FIGURE 1.-Histogram showing sprint trial results for a group of 75 hatchery-reared juvenile European sea bass conducted at CREMA in L'Houmeau, France, in 2001. For each fish, the top velocity reached when swimming through a section of the sprint chamber $0.08 \mathrm{~m}$ or longer is plotted. Each individual swam 4-7 trials over a period of $1-2 \mathrm{~h}$. Mean top sprint velocity was $1.95 \mathrm{~m} /$ $\mathrm{s}(\mathrm{SD}=0.33 \mathrm{~m} / \mathrm{s})$.

sprint trials. Maximal velocity was normally distributed with a coefficient of variation of $17 \%(P$ $>0.05$; Figure 1). Each fish swam at least four times on a given day. Treating the three fastest sprint trials as separate events demonstrated the reliability of the sprint test. Spearman's rank correlation coefficient between an individual's fastest trial and its second fastest trial was $0.883(P<$
0.00001; Figure 2a) and for the second fastest trial versus the third fastest trial was $0.920(P<$ 0.00001 ; Figure $2 b$ ). The mean fastest trial was the 4th trial $(\bar{X}=4.01 \pm 1.6[$ mean $\pm \mathrm{SD}]$; Figure 3 ), suggesting that there might have been a small learning effect on behalf of the fish and that there was no fatigue occurring throughout the testing $(\bar{X}$ $=2.75$ expected if trial number was totally random). However, a chi-square analysis showed that the distribution of fastest trial numbers was not different from random expectation $(P=0.168$; Figure 3). There was no effect of morphology on sprint performance (i.e., no factors generated from a factor analysis of morphological measurements correlated significantly with sprint performance).

\section{Swimming Metabolism}

Corrected swimming metabolism was normally distributed and varied considerably at each swimming speed $(P<0.05$; Figure 4$)$. For each swimming speed, the standard deviation of the rate of oxygen consumption was about $50 \%$ of the mean value (coefficients of variation were 57.5, 49.5, and 39.8 for swimming speeds of $0.45,0.65$, and $0.85 \mathrm{~m} / \mathrm{s}$, respectively). This large variation of metabolism meant that an intermediate rate of oxygen consumption could belong to a fish swimming at any of the three speeds (Figure 4). The first two axes of the morphological factor analysis significantly influenced metabolic rate of fish swimming at a speed of $0.85 \mathrm{~m} / \mathrm{s}$ only. The first factor explained $71 \%$ of the variance in the morphological measurements and was largely a measure of fish
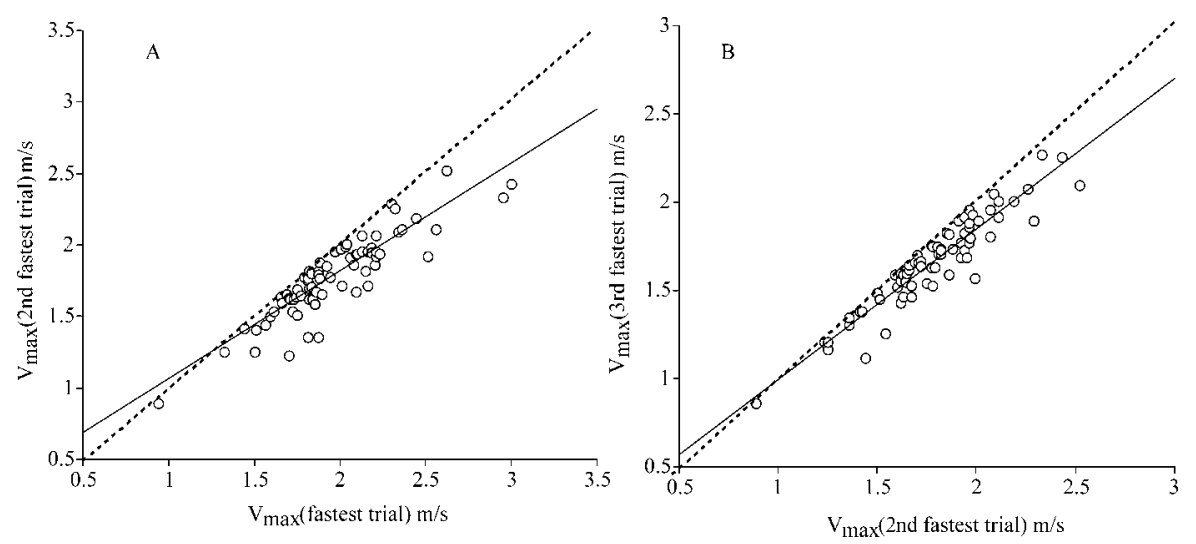

FIGURE 2.- Relationships between sprint trials of 75 hatchery-reared juvenile European sea bass conducted in a sprint chamber at CREMA in L'Houmeau, France, in 2001. Panel (A) shows the highest velocity reached by each individual in its fastest trial run over a period of $1-2 \mathrm{~h}$ graphed against the highest velocity reached by that same individual in its second fastest trial (solid line; the dashed line is the line of identity). Panel (B) shows the highest velocity reached by each individual in its second fastest trial graphed against the highest velocity reached in that same individual's third fastest trial (solid line; the dashed line is the line of identity). 


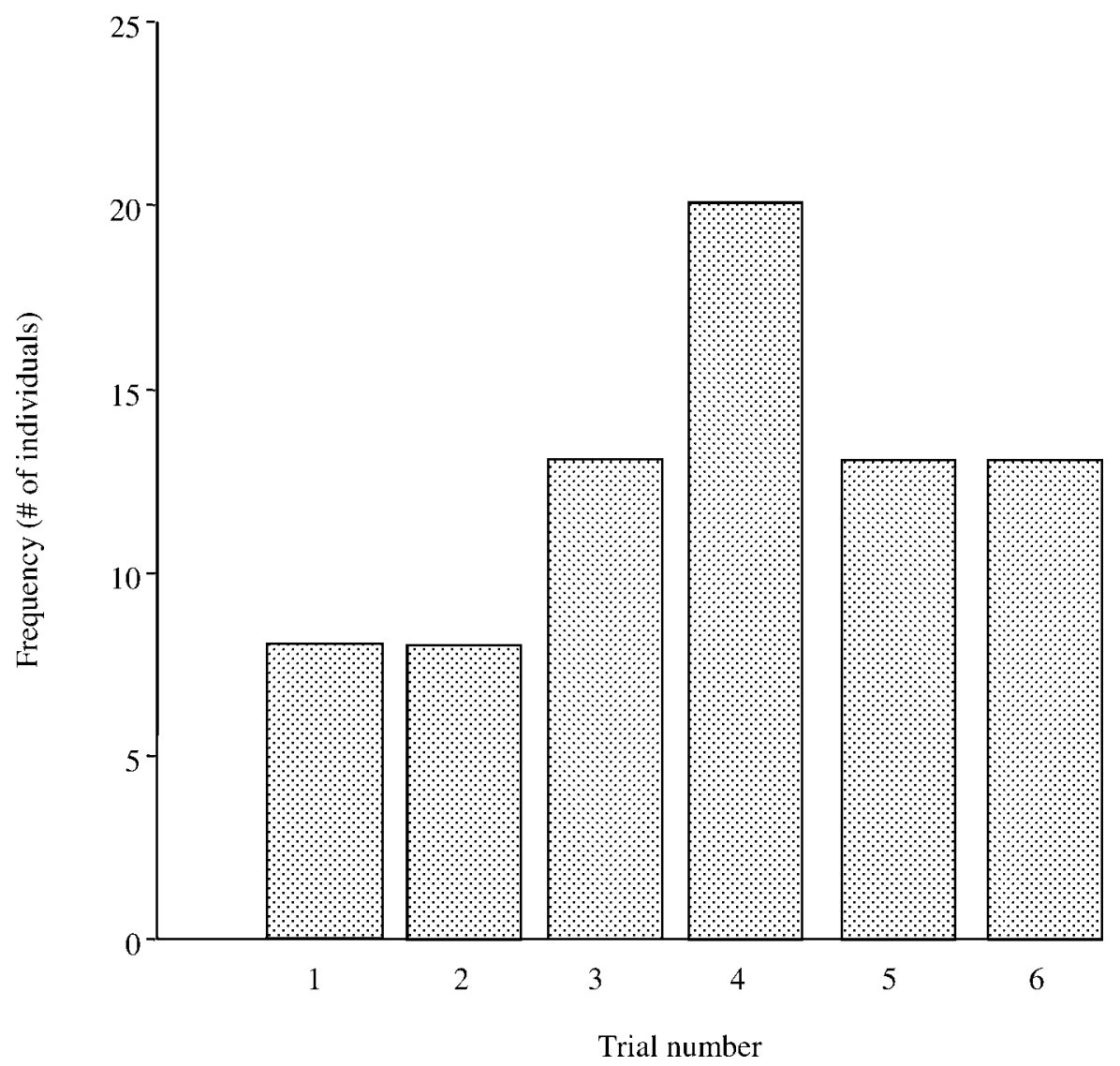

FIGURE 3.- Histogram showing results of sprint trials for a group of 75 hatchery-reared juvenile European sea bass conducted in a sprint chamber at CREMA in L'Houmeau, France, in 2001. For each fish, the trial in which the top velocity was reached is plotted. Most individuals swam 6 trials; however, an individual perceived as responding well to the stimulus may have swum as few as 4 trials and an individual perceived as responding poorly may have swum as many as 7 trials.

size; this factor had a significant influence on the metabolism of fish swimming at $0.85 \mathrm{~m} / \mathrm{s}(P=$ $0.02 ; F=5.66 ; R=0.283)$, suggesting that larger animals consumed relatively more oxygen at this speed despite the previous correction for animal size. The second morphological factor was a measure of a fish's tendency to be relatively wide but not simultaneously deep. This factor had a significant negative influence on the metabolism of fish swimming at a speed of $0.85 \mathrm{~m} / \mathrm{s}(P=0.016 ; F$ $=6.16 ; R=-0.294)$, suggesting that animals that were relatively wide consumed less oxygen at this speed. The rank order of oxygen consumption for fish swimming at a speed of $0.45 \mathrm{~m} / \mathrm{s}$ significantly predicted their subsequent rank order of swimming metabolism at a speed of $0.65 \mathrm{~m} / \mathrm{s}(P<0.05)$, but no other rank comparisons were significant (Figure 4).

\section{Endurance Performance}

The distribution of endurance performances was strongly bimodal (Figure 5). This resulted from two factors: (1) many fish were unable to swim at all at $0.85 \mathrm{~m} / \mathrm{s}$, and (2) many fish that could swim at $0.85 \mathrm{~m} / \mathrm{s}$ were able to swim the entire 2 -h period $(N=25)$. The difference in distance swum between the top performing and least performing fish was $8.5 \mathrm{~km}$. Accordingly, the coefficient of variation of endurance performance was large $(66.7 \%)$. Of the 82 fish that completed the endurance test, $30 \%(N=25)$ swam over $8.5 \mathrm{~km}, 38 \%$ $(N=31)$ exhausted before they swam $2.5 \mathrm{~km}$, and the remaining 26 exhausted between $2.5 \mathrm{~km}$ and $5.1 \mathrm{~km}$. No fish exhausted between 5.1 and 8.5 $\mathrm{km}$. There was no effect of any of the factors generated from a factor analysis of morphological measurements on endurance performance. 


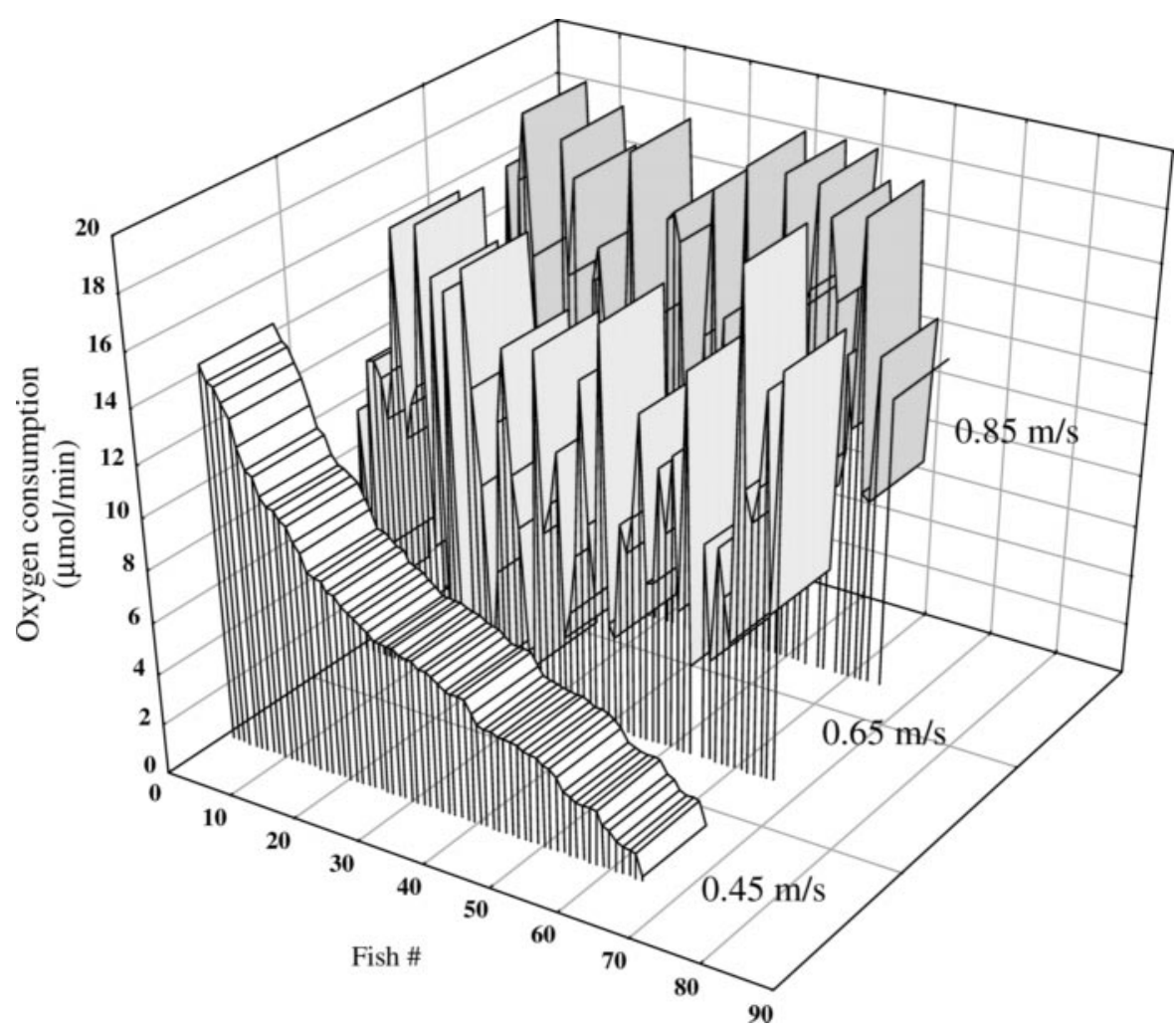

FIGURE 4.- - Histogram of the rate of oxygen consumption in $\mu \mathrm{mol} / \mathrm{min}$ for a group of 72 hatchery-reared juvenile European sea bass swimming at three different swimming speeds in a Brett-type swim tunnel at CREMA in L'Houmeau, France, in 2001. Fish are ordered by descending rate of oxygen consumption at a swimming speed of $0.45 \mathrm{~m} / \mathrm{s}$.

\section{Interrelationships of Performance Measures}

The rate of oxygen consumption at the highest swimming speed $(0.85 \mathrm{~m} / \mathrm{s})$ significantly contributed to the distance that a fish could swim in the endurance test $(P<0.05)$. Otherwise, there were no significant relationships between individual performances in any other tests.

\section{Discussion}

\section{General}

Individual variability of performance measures is an underutilized resource in fish biology (Kolok et al. 1998; Kolok 1999). Since heritable variation is the raw material upon which natural selection operates, knowledge of variability in fitness characters will be an essential first step to predicting selection on fishes in the wild. Management of the economically important European sea bass fishery in Europe is currently based upon traditional fisheries methods (Pickett and Pawson 1994) and does not account for individual differences in fitness.
Knowledge of biological factors that contribute to recruitment of individual fish to the reproducing population could improve management models and should become part of the new "ecosystem approaches" to fisheries management that are evolving (Link 2002). Performance measures can be an important link between selection of the whole animal in nature and the genome (Bennett and Huey 1990). This study was undertaken to examine whether a sprint swimming performance test would be a useful measure in future studies of selection on juvenile European sea bass and related fishes. In addition, we compared sprint swimming performance with two other performance tests and crude assessments of the animal's morphology.

\section{Sprint Performance}

Sprint swimming performance is a relatively rare measurement in fish biology. The vast majority of fish swimming studies have employed in- 


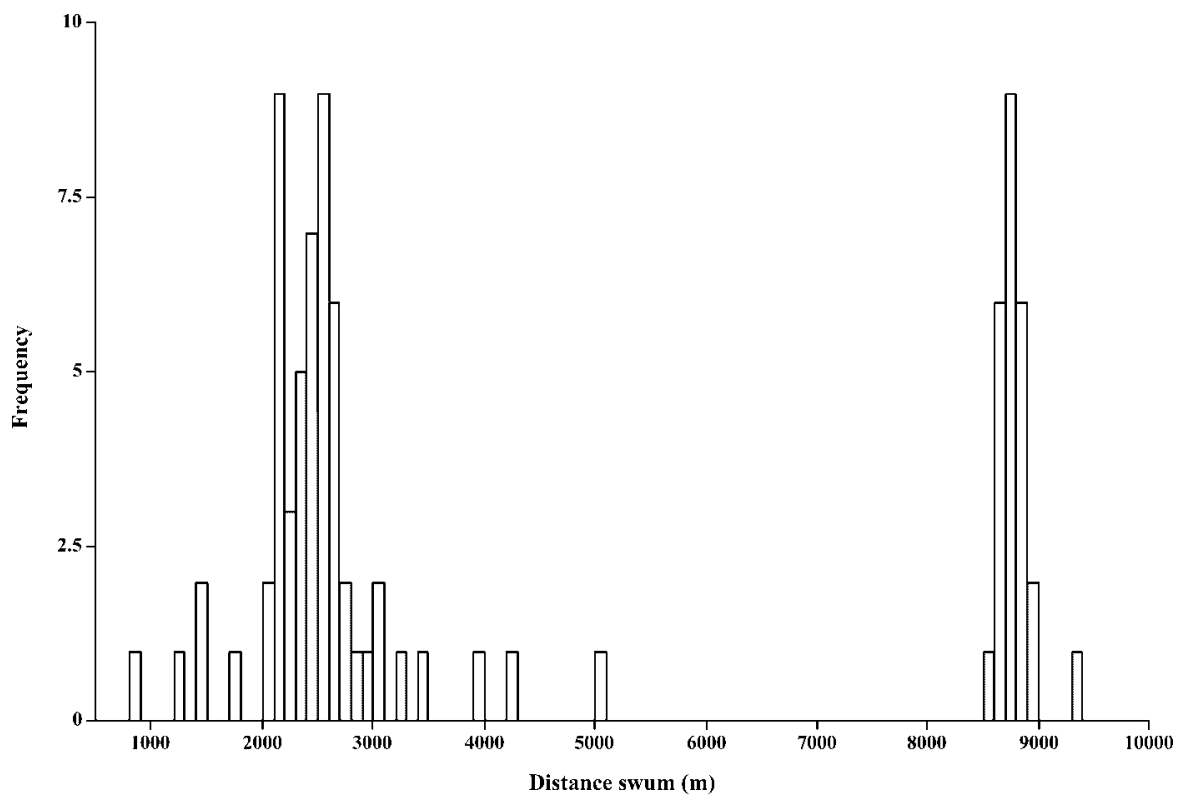

FIGURE 5.-Histogram showing the results of endurance swimming trials of a group of 82 hatchery-reared juvenile European sea bass conducted in a Brett-type swim tunnel at CREMA in L'Houmeau, France, in 2001. The total distance swum in the trial is plotted (after correction for water velocity changes caused by different shapes of fish). The mean distance swum was 4,411.8 $\mathrm{m}(\mathrm{SD}=2,942.9 \mathrm{~m})$.

cremental velocity tests that can last up to several hours (Beamish 1978; Hammer 1995; Plaut 2001; Nelson et al. 2002), whereas the second most common measure of fish swimming performance, faststart performance, occurs in a fraction of a second. Protocols for assessing a fish's fast-start performance generally cover the period from 0 to $60 \mathrm{~ms}$ after initiation of movement (Domenici and Blake 1997). Very few studies have looked at sprint performance on the scale of seconds, a scale that intuitively could have importance for natural selection in a species like European sea bass. Several methods have been employed to look at sprint performance on the scale of seconds, but the method described by Nelson et al. (2002) was employed because of the ease with which large numbers of fish could be repetitively measured and because this measurement has been shown to be repeatable over substantial time intervals in Atlantic cod (Reidy et al. 2000; Martinez et al. 2002).

Use of Nelson et al.'s (2002) sprint performance test with European sea bass actually offered several improvements over its use with Atlantic cod. We were able to exploit the natural tendency of juvenile European sea bass to orient to a dark background and get the fish to position themselves directly in front of the starting line of the sprint chamber. Thus, unrestrained fish could be stimulated to sprint with a quick (attempted) grasp by the investigator, hopefully simulating the response that a large predatory bird striking at the fish from behind would elicit. This method proved to be extremely repeatable on individuals on a daily basis (Figure 2) but also uncovered a threefold variation in maximal performance among the different individual European sea bass in this cohort (Figure 1). Thus, if the method proves to have longer-term repeatability as on Atlantic cod (Reidy et al. 2000; Martinez et al. 2002), it has potential for studies of selection on swimming performance in European sea bass. The results of successive sprint trials on individual European sea bass echo the cautionary note sounded by Losos et al. (2002) for sprint performance of terrestrial animals (Figure 3 ): if the goal of a study is to assess maximum sprint performance of a fish with the method of Nelson et al. (2002), multiple trials must be run. Had less than four trials been run on each European sea bass in this experiment, many individuals would have had their maximal performance underestimated (Figure 3), and the use of only a single trial, as is common practice in many fish performance studies, would have accurately measured maximal performance for only $11 \%$ of the animals. 


\section{Swimming Metabolism}

Oxygen consumption at all three swimming speeds was normally distributed and highly variable (Figure 4). Some of this variability may be attributable to the extensive handling the fish were subjected to; however, having been reared in aquaculture facilities, the animals were accustomed to human contact. This level of variability in metabolic rate is similar to that observed in other European sea bass studies involving less handling (Claireaux and Lagardère 1999) and is also indicative of variance in individual metabolic rates often reported in the literature (Nelson 2002). Nevertheless, although care was taken to minimize human contact and stress during the course of the experiment, a differential response to frequent handling and testing cannot be excluded as partially responsible for the observed variability. Oxygen consumption not only demonstrated high interindividual variability, but also poor intraindividual repeatability in relative rates of metabolism at different swimming speeds. This poor level of connectivity between carefully collected laboratory measures of metabolism at different swimming speeds on the same day suggests that a very large number of trials would have to be run before an accurate assessment of an individual's metabolic rate at a given swimming speed could be made. Since repeat measurements of oxygen consumption on swimming individuals are extremely rare (Reidy et al. 2000), it is impossible to speculate how many measurements would have to be made on an individual before its oxygen consumption at a given swimming speed could be reported with confidence. Reidy et al. (2000) found swimming metabolism to be significantly repeatable in Atlantic cod after 3 months of laboratory residence, but only at high swimming speeds. Plaut and Gordon (1994) found that by using clonal lines of zebra danio Brachydanio rerio they could partition the variance in swimming metabolic rate to be roughly half genetic. Thus, the variability in metabolic rate measurements reported here from closely related animals with a common environmental history might be small compared with what exists in nature. Our conclusion is that swimming metabolic rate is a poor candidate for a laboratory performance measurement to examine evolutionary mechanisms within European sea bass.

Morphology influenced oxygen consumption at $0.85 \mathrm{~m} / \mathrm{s}$. The significant relationship between morphological factor 1 and oxygen consumption at $0.85 \mathrm{~m} / \mathrm{s}$ suggested that larger animals con- sumed relatively more oxygen at this speed, even though the oxygen consumption data had been previously corrected for animal size. A probable explanation is that scaling coefficients in European sea bass may be dependent upon swimming speed as found previously for Atlantic cod (Nelson et al. 1996), and that large fish have an additional metabolic cost to swimming fast, over and above that predicted from scaling of resting metabolic rate. Similarly, Somero and Childress (1980) report that scaling of metabolic enzymes in fish exceeds that expected from the metabolism-size-scaling paradigm. This relationship should be made clearer as more complex morphological measurements are made on a greater size range of animals whose swimming oxygen consumption has been measured. A second significant result was that fish that were relatively deep had greater oxygen consumption at $0.85 \mathrm{~m} / \mathrm{s}$. Since maximum width is usually determined by the epaxial musculature and maximum depth is largely determined by visceral mass, this result makes intuitive sense and has been reported before with more detailed morphological measurements (Boily and Magnan 2002).

\section{Endurance Performance}

The endurance performance test was not successful at producing a normal distribution but certainly uncovered differences in the abilities of this cohort of European sea bass to swim long distances; in fact, the test actually underestimated the true difference in endurance performance that existed in this cohort. Many fish that could have swum longer were stopped after $2 \mathrm{~h}$ of swimming at $0.85 \mathrm{~m} / \mathrm{s}(N=25)$. Although endurance performance tests have provided evolutionary insight in studies of terrestrial vertebrates (e.g., Le Galliard et al. 2004), based upon our experience in this and other studies (Reidy et al. 2000) they have limited utility for pelagic fishes. Selecting a current velocity that illuminates performance differences among individuals and does not require an inordinate amount of time is difficult.

Endurance swimming performance was not influenced by any of the morphological variables, including length. This result was not unexpected since this cohort had been preselected to be homogeneous in size as well as the poor discriminatory power of the endurance test.

\section{Interrelationships of Performance Measures}

The only significant relationship between tests was for $\left[\dot{V} \mathrm{O}_{2}\right]$ of fish swimming at $0.85 \mathrm{~m} / \mathrm{s}$ and endurance performance. The positive correlation 
between oxygen consumption at high swimming speed and endurance performance $\left(U_{\text {crit }}\right)$ has also been found in sockeye salmon Oncorhynchus nerka (Lee et al. 2003). This result could indicate that oxygen uptake is limiting endurance performance in European sea bass, but could also be another manifestation of the significantly higher "masscorrected" oxygen consumption of the larger fish. Otherwise, each performance test appeared to be measuring different aspects of the fish's biology, or the large variability prevented relationships from being ascertained, even with the large sample size. When looking at the interrelationships between different performance measurements made on individual European sea bass, one can either find tradeoffs between performances in the different tests, positive correlations among the performance tests, or find that the tests are independent of one another. Our findings provide limited support for the "independence" hypothesis for European sea bass, which is also the most frequent finding in studies of locomotor performance of terrestrial animals (Bennett and Huey 1990). The sprint swimming performance test described here holds promise for studying selection on locomotor performance in fishes similar to the European sea bass; however, the measurement of swimming metabolic rate and the endurance test described here were judged to be of little utility in this regard.

\section{Acknowledgments}

We would like to thank Jeff Klupt, Gaël Guillou, Michel Prineau, and Hervé Chartois for technical assistance. We would also like to thank Robert G. Boutilier for bringing us together in an environment that encouraged new ways to look at fish physiology and two anonymous reviewers for their useful suggestions. This study was supported by Conseil Régional Poitou-Charentes (France) and Towson University (USA).

\section{References}

Beamish, F. W. H. 1978. Swimming capacity. Pages 101-187 in W. S. Hoar and D. J. Randall, editors. Fish physiology, volume 7. Academic Press, New York.

Bell, W. H., and L. D. B. Terhune. 1970. Water tunnel design for fisheries research. Fisheries Research Board of Canada Technical Report. 195.

Bennett, A. F., and R. B. Huey. 1990. Studying the evolution of physiological performance. Pages 251283 in D. J. Futuyma and J. Antonovics, editors. Oxford surveys of evolutionary biology, volume 7. Oxford University Press, Oxford, UK.

Billerbeck, J. M., T. E. Lankford, and D. O. Conover.
2001. Evolution of intrinsic growth and energy acquisition rates, I. Tradeoffs with swimming performance in Menidia menidia. Evolution 55:18631872 .

Boily, P., and P. Magnan. 2002. Relationship between individual variation in morphological characters and swimming costs in brook charr (Salvelinus fontinalis) and yellow perch (Perca flavescens). Journal of Experimental Biology 205:1031-1036.

Claireaux, G., and J.-P. Lagardère. 1999. Influence of temperature, oxygen, and salinity on the metabolism of the European sea bass. Journal of Sea Research 42:157-168.

Claireaux, G., D. M. Webber, S. R. Kerr, and R. G. Boutilier. 1995. Physiology and behaviour of freeswimming Atlantic cod (Gadus morhua) facing fluctuating salinity and oxygenation conditions. Journal of Experimental Biology 198:61-69.

Domenici, P., and R. W. Blake. 1997. The kinematics and performance of fish fast-start swimming. Journal of Experimental Biology 200:1165-1178.

Gregory, R. T., and C. M. Wood. 1998. Individual variation and interrelationships between swimming performance, growth rate, and feeding in juvenile rainbow trout (Oncorhyncus mykiss). Canadian Journal of Fisheries and Aquatic Sciences 55:15831590 .

Hammer, C. 1995. Fatigue and exercise tests with fish. Comparative Biochemistry and Physiology 112A: $1-20$.

Kolok, A. S. 1999. Interindividual variation in the prolonged locomotor performance of ectothermic vertebrates: a comparison of fish and herpetofaunal methodologies and a brief review of the recent fish literature. Canadian Journal of Fisheries and Aquatic Sciences 56:700-710.

Kolok, A. S., E. P. Plaisance, and A. Abdelghani. 1998. Individual variability in the swimming performance of fish: an overlooked source of variation in toxicology studies. Environmental and Toxicological Chemistry 17:282-285.

Le Galliard, J. F., J. Clobert, and R. Ferriere. 2004. Physical performance and Darwinian fitness in lizards. Nature (London) 432:502-505.

Lee, C. G., A. P. Farrell, A. Lotto, M. J. MacNutt, S. G. Hinch, and M. C. Healey. 2003. The effect of temperature on swimming performance and oxygen consumption in adult sockeye (Oncorhyncus nerka) and coho $(O$. kisutch) salmon stocks. Journal of Experimental Biology 206:3239-3251.

Link, J. S. 2002. What does ecosystem-based fisheries management mean? Fisheries 27(4):18-21.

Losos, J. B., D. A. Creer, and J. A. Schulte II. 2002. Cautionary comments on the measurement of maximum locomotor capabilities. Journal of Zoology (London). 258:57-61.

Martinez, M., H. Guderley, J. A. Nelson, D. M. Webber, and J.-D. Dutil. 2002. Once a fast cod, (Gadus morhua), always a fast cod: maintenance of performance hierarchies through changing food availability. Physiological and Biochemical Zoology 75: 90-100. 
Nelson, J. A. 2002. Metabolism of three species of herbivorous loricariid catfishes: influence of size and diet. Journal of Fish Biology 61:1586-1599.

Nelson, J. A., P. S. Gotwalt, S. P. Reidy, and D. M. Webber. 2002. Beyond $U_{\text {crit }}$ : Matching swimming performance tests to the physiological ecology of the animal, including a new fish "drag strip". Comparative Biochemistry and Physiology 133A:28930.

Nelson, J. A., Y. Tang, and R. G. Boutilier. 1996. The effects of salinity change on the exercise performance of two Atlantic cod (Gadus morhua) populations inhabiting different environments. Journal of Experimental Biology 199:1295-1309.

Pawson, M. G., and G. D. Pickett. 1987. The bass, Dicentrarchus labrax, and management of its fishery in England and Wales. Ministry of Agriculture, Fisheries and Food (MAFF), Directorate of Fisheries Research, Lab. Leaflet 59, Lowestoft, UK.

Pickett, G. D., and M. G. Pawson. 1994. Sea bass: biology, exploitation, and conservation. Chapman and Hall, London.
Plaut, I. 2001. Critical swimming speed: its ecological relevance. Comparative Biochemistry and Physiology 131 A:41-50.

Plaut, I., and M. S. Gordon. 1994. Swimming metabolism of wild-type and cloned zebrafish (Brachydanio rerio). Journal of Experimental Biology 194: 209-223.

Reidy, S., S. R. Kerr, and J. A. Nelson. 2000. Aerobic and anaerobic swimming performance of individual Atlantic cod. Journal of Experimental Biology 203: 347-357.

Slinker, B. K., and S. A. Glantz. 1985. Multiple regression for physiological data analysis: the problem of multicollinearity. American Journal of Physiology 249:R1-R12.

Somero, G. N., and J. J. Childress. 1980. A violation of the metabolism-size scaling paradigm: Activities of glycolytic enzymes in muscle increase in largersize fish. Physiological Zoology 53:322-337.

StatSoft. 1994. Statistica for the Macintosh (volume 1). StatSoft, Tulsa, Oklahoma. 